\title{
Olive pomace based lightweight concrete, an experimental approach and contribution
}

\author{
Chaabane Lynda Amel ${ }^{1}$ and Benferrah Rafik ${ }^{1}$ \\ ${ }^{1}$ Djillali Liabes University, Civil Engineering Department, Environment and Civil Engineering Laboratory, \\ Sidi Bel Abbes, Algeria
}

\begin{abstract}
Due to conventional aggregates resources depletion, material recycling has become an economic and ecologic alternative. In this paper, locally available natural residues such as olive pomace were investigated, when partially incorporated in the concrete formulation, since the mechanical characteristics of lightweight aggregate concrete strongly depend on its properties and proportions. Lightweight aggregates are more deformable than the cement matrix because of their high porosity, and their influence on the concrete strength remains complex. The purpose of this paper is to investigate the aggregates properties on lightweight concrete mechanical behaviour through an experimental approach. In addition, the different substitution sequences and the W/C ratio on lightweight concrete behaviour were evaluated, in order to determine the W/C ratio influence on the improvement of the lightweight concrete mechanical properties while knowing that the mixing water quantity gives the cement paste manoeuvrability and mechanical strength effects. The last part of this paper, therefore, was to provide statistical survey for estimating strength and weight reduction through the different natural aggregate substitutions to improve the lightweight concrete properties. The results achieved in a significant olive-pomace lower adhesion with the matrix after the cement setting, making the lightweight concrete mechanical strength weak. However, this work can open several perspectives: Results modeling and correlation with an experimental approach, the evolution and determination of lightweight concrete characteristics when exposed to high temperatures and thermohydric properties.
\end{abstract}

\section{Introduction}

In this article, we wish to show that the building sector, being so polluting, can now become an ecological lung in terms of recycling waste to obtain ecological concrete. Moreover, in the construction of a certain number of structures, weight reducing lead to general cost-savings, concrete density may vary between 0.5 to 2 when using lightweight aggregates, but because the concrete has less density, then its compressive strength is lower [1]. Conventional aggregate resources are becoming increasingly depleted over the years, especially in the Saharan areas. These materials are expensive to store and storage sites are also scarce, environmental standards restrict the use of toxic materials. In addition, more processing is required for materials originating from natural environment involving treatment and crushing stations, and therefore, the cost of natural aggregate manufacture is high. That's why part of material recycling remains the best and effective option. [2].

Because the Algerian industry produces huge quantities of olive-pomace every year, lightweight concrete was composed with a variety of olive-pomace aggregates mixtures (731.332t) [3]. The objective of this experimental approach is to demonstrate that the lightweight concrete mechanical behaviour is affected by the aggregate porous properties when inserted in the cement formulation, making it more complex in terms of maneuverability and strength.

\section{Experimental materials and procedures}

Conventional concrete can be chosen via many methods, in our study case, the method of [4] was applied, which consists of making mixtures with different aggregates. The objective here is to produce an insulating concrete [1]. The S / C ratio remains constant, for all tests we use moulds $\varnothing 16 \mathrm{~cm} \times 32 \mathrm{~cm}$, filled almost equally in three layers, this is to determine the lightweight aggregates influence on the lightweight concrete mechanical behaviour, $16 \times 32 \mathrm{~cm}$ test tubes were made with a variable matrix and a different aggregates percentage.

During material mixing, the subsidence of Abrams cone and density were determined for each batch, density is used to possibly correct the mixtures proportions [5]. 
- The matrix is made of CPJ-CEM II / A 42.5 cement mortar and non-core sand [6].

\subsection{Sand of Sidi Bel Abbès area(Algeria)}

The report covers the majority of analysis results led by the Laboratory of the engineering department on the sand quarry of Sidi Bel Abbes area.

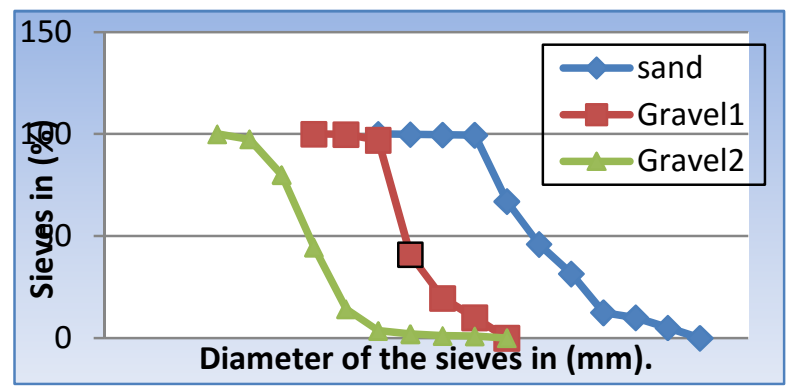

Fig1. Aggregates granulometric analysis.

By curve analysis, we found out that the gravel granulometry and alluvial sand has a continuous shape which will affect the concrete quality, durability and strength.

\subsubsection{Physical properties}

Alluvial sand from the area of Sidi Bel Abbes (North West Algeria). The equivalent of sand [7] shows that it is clean, and good for a quality concrete. The characteristics are reported in table. 1 below.

Table.1. Sand physical characteristics

\begin{tabular}{|l|l|l|}
\hline Characteristics & Unit & Sand \\
\hline Absolute density & $\mathrm{g} / \mathrm{cm}^{3}$ & 2.7 \\
\hline Bulk density $\%$ & $\mathrm{~g} / \mathrm{cm}^{3}$ & 1.63 \\
\hline Sand Equivalent & $\%$ & 73.5 \\
\hline Absorption degree & $\%$ & 1.00 \\
\hline
\end{tabular}

\subsection{Cement constituents}

The CPJ-CEM II/A 42.5 Portland cement is obtained through the finely ground mixture of clinker and additives, calcium sulphate is added as gypsum to regulate the setting [8].

\section{Composition}

CPJ-CEM II/A 42.5 Compound Portland cement consists of:

80 to $94 \%$ of Portland clinker.

6 to $20 \%$ at maximum of additives (pure limestone).
Minor constituents ( 0 to $5 \%$ Calcium sulphate is added as a setting regulator).

Table 2. Cement physical properties [8]

\begin{tabular}{|c|c|}
\hline $\begin{array}{l}\text { Cement } \\
\text { ECDE-Chlef cement factory } \\
\text { (Algeria) }\end{array}$ & Standard NA442 \\
\hline $\begin{array}{l}\text { Initial setting }>60 \mathrm{~mm} \\
\text { Heat stability }<7 \mathrm{~mm}\end{array}$ & $\begin{array}{l}\text { Initial setting } \geq 60 \mathrm{~mm} \\
\text { Heat stability } \leq 7 \mathrm{~mm}\end{array}$ \\
\hline Removal 28 days $<650 \mu \mathrm{m}$ & Removal 28 days $\leq 650 \mu \mathrm{m}$ \\
\hline
\end{tabular}

\subsubsection{Chemical Analysis}

Table 3 . Cement chemical composition

\begin{tabular}{|l|l|l|l|l|}
\hline Element & $\begin{array}{l}\mathrm{SiO}_{3} \\
(\mathrm{NA442})\end{array}$ & $\begin{array}{l}\text { Chlorides } \\
(\mathrm{NA442})\end{array}$ & $\begin{array}{l}\mathrm{SiO}_{3} \\
(\mathrm{ECDE})\end{array}$ & $\begin{array}{l}\text { Chlorides } \\
(\mathrm{ECDE})\end{array}$ \\
\hline$\%$ & $\leq 3.5$ & $\mathrm{Cl}-\leq 0.1$ & $\leq 2.00$ & $\begin{array}{l}\mathrm{Cl}- \\
\leq 0.08\end{array}$ \\
\hline
\end{tabular}

\subsection{Aggregates choice}

The choice fell on the olive-pomace based lightweight concrete "fig. 2" from the area of Sig (Wilaya of Mascara - Algeria), due its abundance and important natural features [9].
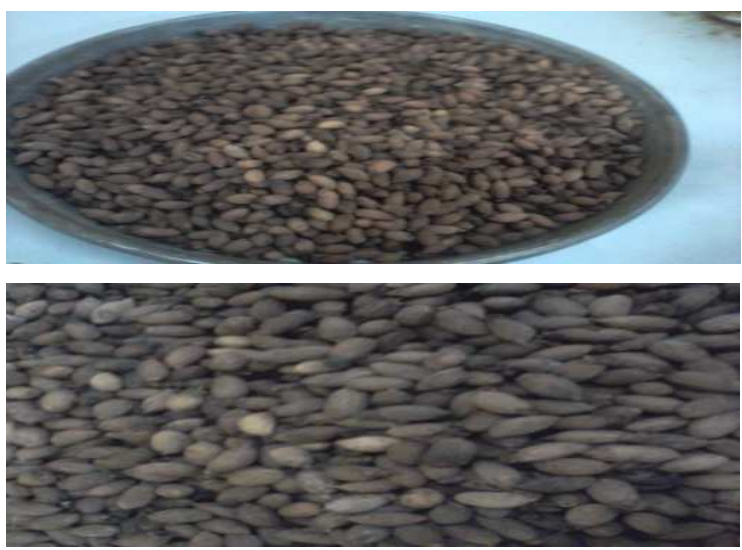

Fig.2. Olive-pomace based lightweight concrete.

Knowing that the mechanical properties of lightweight concrete strongly depend on its aggregates proportions present in the concrete formulation, in particular due to their high porosity, lightweight aggregates are more deformable than the cement matrix and have a complex influence on the concrete strength.

As part of the previous research carried out on lightweight concretes, this one aims to understand the behaviour of light aggregates, an experimental part was carried out where the olive pomace was pre-wetted before being introduced into the mixtures, the absorption rate reached $35 \%$ during the first days, followed by a longterm stabilization. 
Table 4.Olive-pomace physical properties.

\begin{tabular}{|l|l|}
\hline Physical properties & Olive-pomace \\
\hline Density $\left(\mathrm{g} / \mathrm{cm}^{3}\right)$ & 0.9 \\
\hline Mean particle diameter & $8 \mathrm{~mm}$ \\
\hline Max. particle diameter & $12 \mathrm{~mm}$ \\
\hline
\end{tabular}

\subsection{Adjuvant}

The adjuvant is a plasticizer that helps to decrease the water quantity in the cement matrix and to increase the mechanical strength. These additives help reduce the $\mathrm{W} / \mathrm{C}$ ratio.

\section{Results and discussions:}

\subsection{Lightweight concrete formulation}

Through this experimental work, the lightweight concrete is formulated of olive pomace aggregates, using Dreux formulation methods, to determine the substitution rate, rheology and compactness of light concretes.

Table .5: Different compositions of $1 \mathrm{~m}^{3}$ of lightweight concrete.

\begin{tabular}{|l|l|}
\hline Concrete & $\mathrm{G} / \mathrm{S}$ \\
\hline BLGO1 & 0.6 \\
\hline BLGO2 & 0.68 \\
\hline BLGO3 & 0.75 \\
\hline BLGO4 & 0.8 \\
\hline BLGO5 & 1.00 \\
\hline BLGO6 & 1.2 \\
\hline
\end{tabular}

\subsection{Lightweight aggregates effects on mechanical properties.}

On the basis of elementary formulations, by varying the $\mathrm{W} / \mathrm{C}$ ratio as well as olive pomace substitution in the concrete preparation, then correcting the $\mathrm{G} / \mathrm{S}$ ratio to 1.20 , in a way to introduce this ratio in our final composition, in order to achieve objectives.

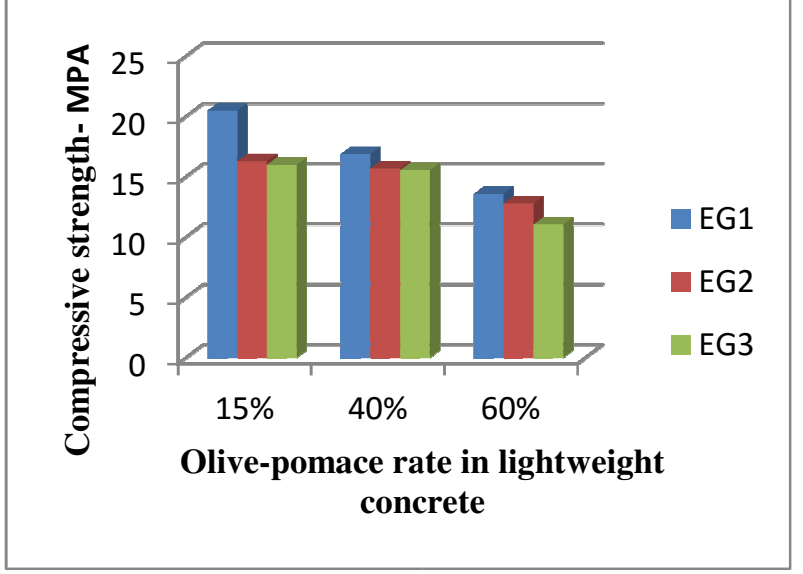

Fig.3. Concrete compressive strength

It can be seen from "fig. 3" that the olive-pomace-based concrete has low compressive strength than conventional (light) concretes, the compressive strength decreased by increasing the olive pomace dosage.

The decreasing resistance throughout 28 days depends on the nature and the substitution rate of the natural aggregates as well as the cement dosage.

The lightweight aggregates concrete strength is determined by the concrete composition, through the W/ C ratio "fig. 3", the Aggregate/Sand volume ratio and the Cement content. The concrete strength is higher if the $\mathrm{W}$ / C ratio is lower [10]. However, too little water may not be able to completely hydrate the cement and may lead to a concrete strength drop and may limit the variations in the $\mathrm{W} / \mathrm{C}$ ratio during the concrete manufacture due to high aggregates absorbency, which must be saturated and drained [5].

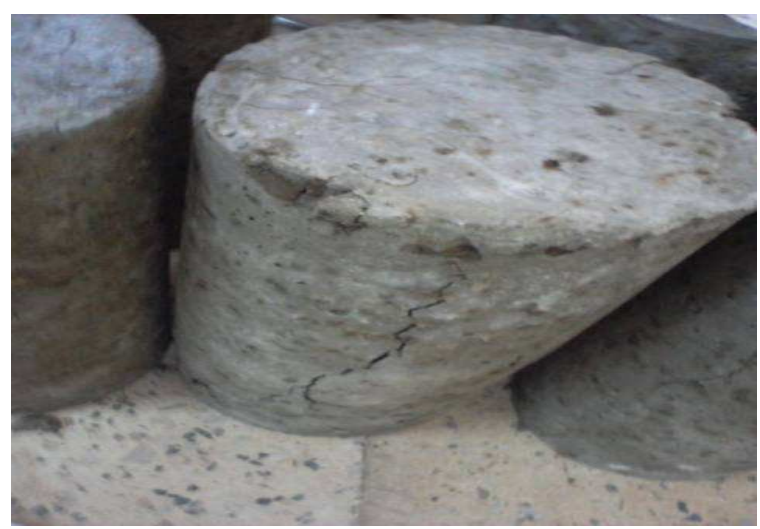

Fig.4. Test tube crack line subjected to the compression test.

"Fig. 4" illustrates fracture lines corresponding to the simulations carried out by [5]. It demonstrates the the maximum stress of the lightweigh concrete is along $\mathrm{Oz}$ axis "Fig. 3" and picture 4", however, the maximum 
stress of the conventional concrete is along Ox axis, according to [5].

\subsection{Void volume variation based on $\mathrm{W} / \mathrm{C}$ ratio}

The notion of compactness, being an intrinsic characteristic of the mixture had to be well defined during the solid suspension elaboration. In practice, they were random mixtures, so the aim was to fill the space with granular materials of different densities. For this purpose, the relationship between minimal porosity and granular extent was investigated.

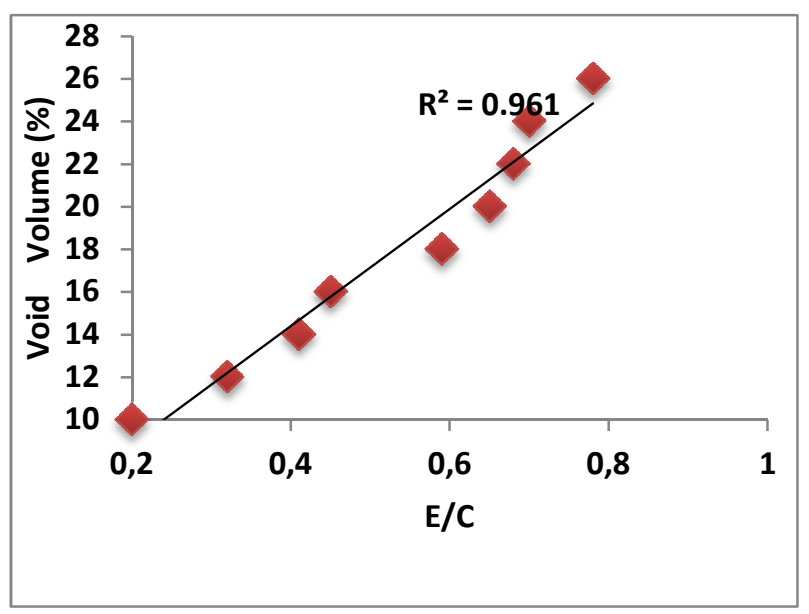

Fig. 5. Void volume variation based on W/C ratio at $60^{\circ} \mathrm{C}$.

In order to improve the processing and the compaction, and to reduce the concrete porosity, many tests have been carried out on the water content measurement of lightweight concrete by making hydrostatic weighing tests on olive pomace-based lightweight concrete at $60^{\circ}$ $\mathrm{C}$, the results shown in "Fig. 5" show that the drying temperature affects the material characteristics, the prewetting of the lightweight aggregates proved to be an essential part in the manufacture of lightweight concrete by granting it a long-term fundamental kinetics affecting the hydration of the cement. There is a good correlation between the void volume and the $\mathrm{W} / \mathrm{C}$ ratio, as demonstrated by [10].

\section{4 compressive strength evolution based on W/C ratio.}

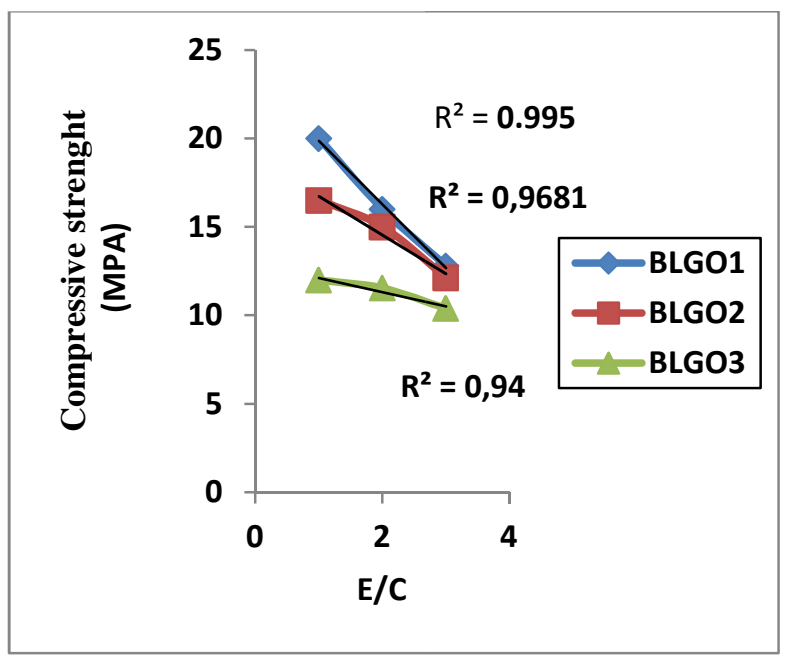

Fig. 6. Compressive strength evolution based on W/C ratio.

The lightweight aggregate concrete resistance is controlled by the following elements:

- the concrete composition, through the $\mathrm{W} / \mathrm{C}$ ratio "Fig. 6".

- the Aggregate/Sand volume ratio.

- the cement content.

The compressive strength of the concrete is higher than the W/C ratio, that is to say the water quantity is low [11]. However, too little water may not be able to fully hydrate the cement, and may lead to a concrete strength drop, and possibly limit the variations of the $\mathrm{W} / \mathrm{C}$ ratio during the concrete manufacture high aggregates absorbency, which must be saturated and drained [5].

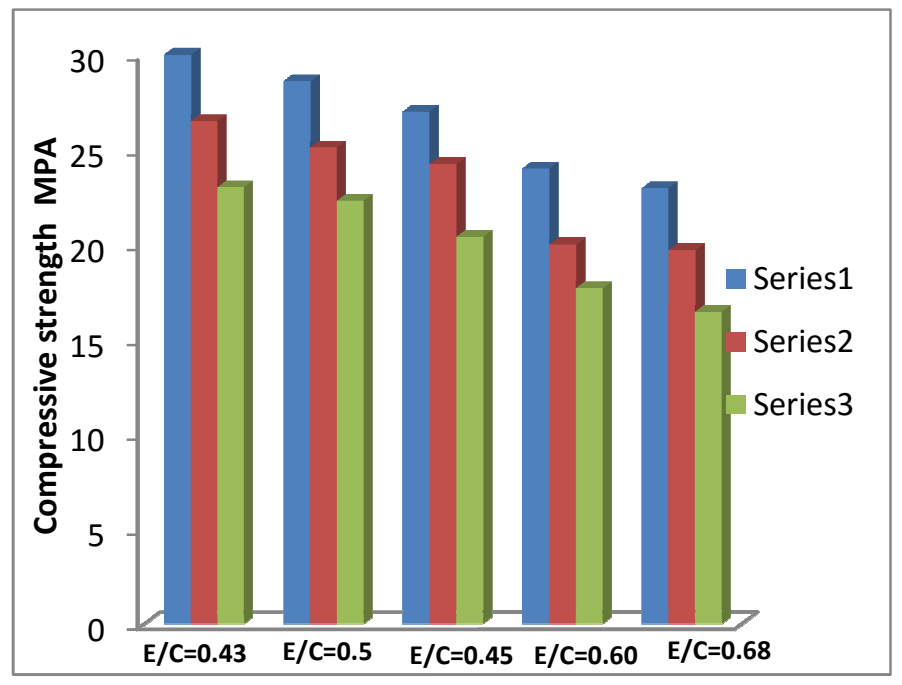

Fig.7. Compressive strength variation based on W/C ratio.

It is seen from "Fig. 7" that the olive-pomace based concrete have lower compressive strength than conventional (light) concrete, and that the strength drop decreases by increasing the cement dosage. The resistence drop throughout 28 days depends on the nature 
and the substitution rate of the natural aggregates as well as the cement dosage.

\subsection{Water quantity influence on the concrete compressive strength}

The water quantity is a major factor that impacts on the lightweight concrete strength, since lightweight aggregates undergo pre-wetting before they are introduced into the mixture, the amount of water added will be directly related to the effective $\mathrm{W} / \mathrm{C}$ ratio.

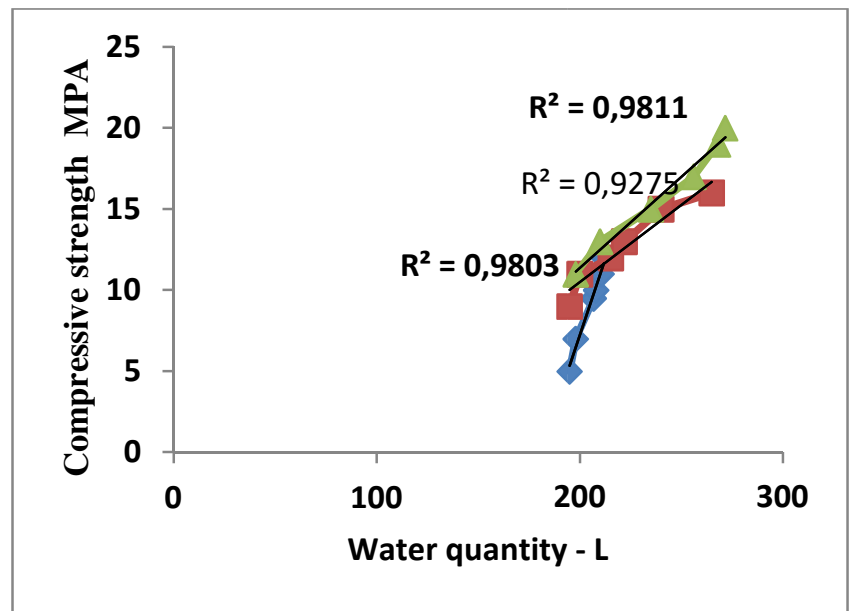

Fig. 8. Compressive strength and the mixing water relation.

"Fig. 8" represents the concrete mixtures with a variation in the W/C ratio, the quantity actually used (mixing water) to increase subsidence in accordance with natural aggregate substitution rate.

"Fig. 8" shows that the evolution according to the quantity of water added to the olive-pomace-based concrete and the conventional lightweight concrete have similar behaviour, this leaves us to conclude that the cement hydration is normal. Finally, the substitution rate of natural aggregate concrete does not exceeding 35\%, have an acceptable long-term resistance. As a conclusion, the strength drop rises slightly in the course of time for each lightweight concrete composition.

\subsection{Elastic properties of lightweight aggregates}

It is hard to describe the grain strength in lightweight aggregates; it has more elastic properties [12].

It can also be seen that their high porosity reduces the wall effect, and the transition zone are different to the normal aggregates. The thin interfacial zone is characterized by mechanical and chemical linkage between the paste and the facial aggregates as defined by different authors $[13,14]$.

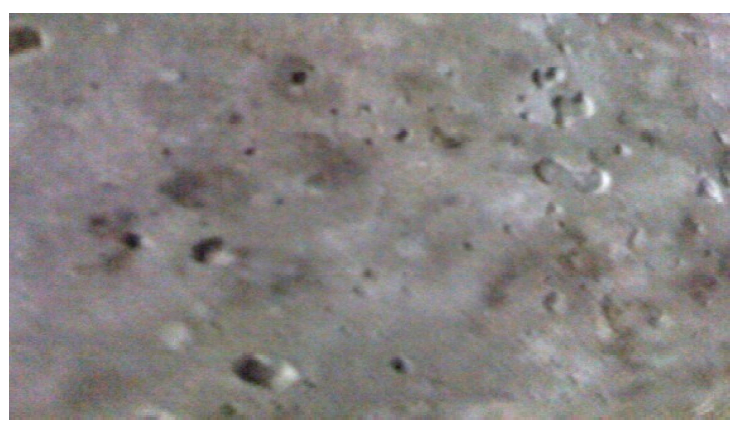

Fig. 9. Picture enlargement of the cement matrix.

\subsection{Concrete test tubes subjected to compression}

A group of test tubes subjected to the same test should appear more or less identical to the naked eye, however, these test tubes contain structural defects of various sizes, up to the microscopic scale. For this purpose, Weibull distribution is presented in case of uniaxial stress, using it to test material resistance under simple sollicitations. The ability to resist fractures is undoubtedly one of the most important and most studied characteristics of materials. A fracture of a material is the separation into two or more pieces under stress [15].

In many areas such as building, this ability to resist breakage is considered as safety feature. Question is: What is the maximum stress that can be applied so that the probability of fracture is less than $1 \%$.

A statistical survey will be applied on these data in order to reduce the maximum stress on lightweight concrete so that the probability of rupture is less than $1 \%$ [15].

It is clearly seen on the obtained curve the fact that Weibull distribution was used:

$\operatorname{Ln}[\operatorname{Ln}(1 / \mathrm{Ps})]=\mathrm{m}[(\operatorname{Ln}(\sigma)-\operatorname{Ln}(\sigma 0)]$

Where m: Weibull modulus.

$\sigma 0$ : scaling parameter.

$\sigma:$ The probability of survival.

\section{a- The assumptions}

The weibull distribution is based on two simple assumptions, which we present here:

1-The fracture strength of each volume element is modelled by independent variables. The randomness aspect makes allows taking into account the dispersion; Independent sub-volumes imply that there is no interaction between infinitesimal volumes, which means that the fracture is a purely punctual phenomenon [16].

2 - The fracture of the infinitesimal volume containing the first activated fault brings about the ruin of the inspected structure: in other words: as soon as the fracture occurs, the mechanical functions of the whole piece are lost [16]. 


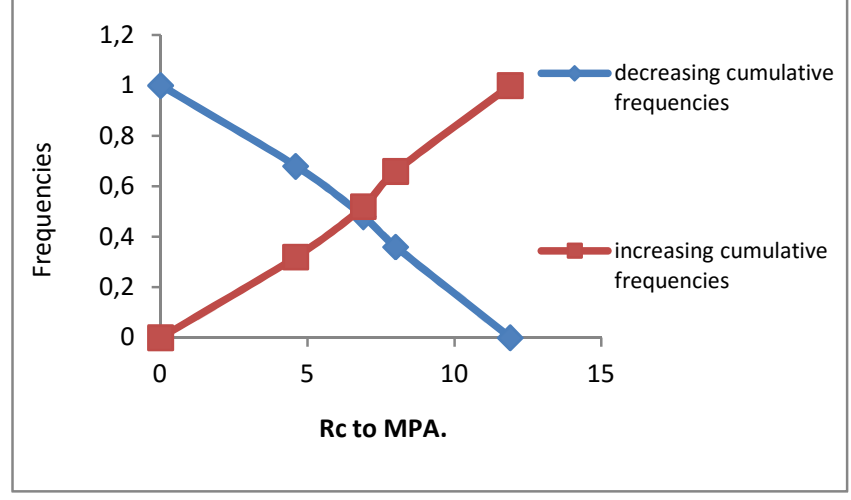

Fig. 10. Cumulative frequencies of lightweight concrete test tubes subjected to compression.

The curve in "Fig. 10" where $\mathrm{m}=3.1$, shows that Weibull modulus is lower, so the dispersion on fracture stress is higher. In a series of test tubes, the median one corresponds to the value chain having a cumulative increasing and decreasing frequency corresponding to a median value class of 0.5 , this may result in manipulation errors which reduce the crushing test perfection rate of the lightweight concrete tubes as confirmed by [15].

A concrete element does not break under the effect of a single stress but under the effect of several stresses. The test tubes results can't be taken into account to estimate the concrete strength, only if the stress field is of the same type in both cases [17].

\section{Conclusions}

The main objective of this study is to technically demonstrate the possibility to use aggregates (olive pomace) in the manufacture of ecological concrete.

The present study shows that olive pomace can reduce the concrete test tubes weight and can be used as a mass substitution additive at an optimum rate of $35 \%$. Throughout this paper, it was concluded that olive pomace had a poor adhesion with the cement matrix after the setting, because of its irregular shape, in addition, the outer side of the olive pomace is rough and let not form granular skeleton that generates the mechanical work of the lightweight concrete.

\section{References}

1. El Bakkouri A.Etude thermomécanique du beton allege avec du liege et du beton allege avec des grignons d'olives. 12 èmes Journées Internationales de Thermiques ,France (2005).

2.E-H.Benaichi .Etude des bétons à base des sables de démolition et ajouts minéraux actifs. Thèse de Magister, Université mohamed khider Biskra, Algeria (2009).

3. L. Touati ., Valorisation des grignons d'olive Etude de cas: Essai de valorisation en Biocarburant .Thèse
Magister ,Université M'hamed Bougara-Boumerdes, Algerie (2013).

4. G.Dreux ,F.Gorisse. Composition des bétons: méthode Dreux -Gorisse .Annales de L'ITBTP, $\mathrm{n}^{\circ} 414$ (1983).

5. Yang Ke.Caracteristion du comportement mécanique des bétons de granulats legers:Experience et modélisation.Phd.D.Thesis, université de Cergy-Pontoise ,France (2008).

6.Y.LOT,Z.CUI H.Effect of porous lightweight aggregate on strength of concrete . Materials letters ,58,P 916-919 (2004).

7. NF. Equivalent de sable P18-597 (1991).

8. http:// www.ecde.dz la norme NA 442-200.

9.H. EZBAKHE. Caractéristiques thermiques de matériaux poreux utilisés comme isolant simples et porteurs . Phd.D.Thesis, U.C.B.Lyon, France (1986).

10. G. COQUILLAT, L. HASNI. Projet national CALIBE -Fabrication du béton, Mesure des teneurs en eau des bétons durcis CEBTP ; centre expérimental de recherches et d'études et des travaux publics direction de la recherche et des affaires scientifiques et techniques ;DRAST ; Ministère de l'équipement .Saint Rémy-Les-Chevreuse :CEBTP(1999).

11. D.MORIN .Sur les bétons légers et leur comportement sous des sollicitations biaxiales. Phd.D.Thesis ,Université Paul Sabatier de Toulouse ,France (1976).

12.J. Muller Rochholz .Determination of the elastic properties of lightweight aggregate by ultrasonic pulse velocity measurement ,the international journal of light weigh concrete,1,p 87-90(1979).

13.Y.LOT.Y.,Z.CUI H. Effect of porous lightweight aggregate on strength of concrete ; Materials letters , 58, p 916-919 (2004).

14. Y.LOT.Y.,Z.CUI H. Spectrum analysis of the interfacial zone of lightweight aggregate concrete ,materials letters,58,p 916-919(2004).

15.J.B LEPRETRE. Compte -rendu de Travaux dirigés Statistique de Weibull, deuxième année Cours électif CE42 ;Matériaux pour l'ingénieur Année universitaire (2009-2010).

16. S.GRANGE J-L PRENSIER. Le module de Weibull un critère de rupture probabiliste . Université PARISSACLAY ENS de Cachan ,France. (Ed .),(01-07-2006).

17. http://www.e-periodica.ch. Essais statistiques sur mortiers et béton. Prot, Marcel 3 (1948). 